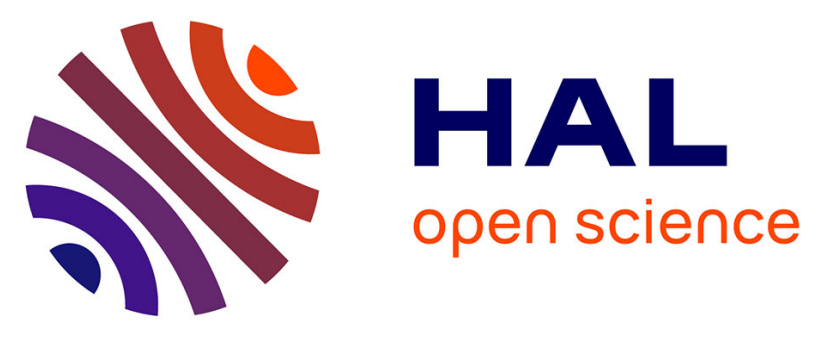

\title{
Spatial evidence of cross-crop pesticide contamination in small-holder Thai farms
}

Rachel Dunn, C. Anderson, Michael Walter, Warinthorn Songskiri, Chawis Srimanee, Pattarin Thunyapar, Tammo Steenhuis

\section{- To cite this version:}

Rachel Dunn, C. Anderson, Michael Walter, Warinthorn Songskiri, Chawis Srimanee, et al.. Spatial evidence of cross-crop pesticide contamination in small-holder Thai farms. Agronomy for Sustainable Development, 2014, 34 (4), pp.773-782. 10.1007/s13593-013-0192-3 . hal-01234812

\section{HAL Id: hal-01234812 \\ https://hal.science/hal-01234812}

Submitted on 27 Nov 2015

HAL is a multi-disciplinary open access archive for the deposit and dissemination of scientific research documents, whether they are published or not. The documents may come from teaching and research institutions in France or abroad, or from public or private research centers.
L'archive ouverte pluridisciplinaire HAL, est destinée au dépôt et à la diffusion de documents scientifiques de niveau recherche, publiés ou non, émanant des établissements d'enseignement et de recherche français ou étrangers, des laboratoires publics ou privés. 


\title{
Spatial evidence of cross-crop pesticide contamination in small-holder Thai farms
}

\author{
Rachel A. Dunn • C. Lindsay Anderson - Michael F. Walter • Warinthorn Songskiri • \\ Chawis Srimanee $\cdot$ Pattarin Thunyapar $\cdot$ Tammo S. Steenhuis
}

Accepted: 22 October 2013 /Published online: 11 December 2013

(C) INRA and Springer-Verlag France 2013

\begin{abstract}
Development efforts for the reduction of land use needs and the improvement of farmer livelihoods in northern Thailand have resulted in the introduction of new pesticideintensive crop species. Cholinesterase-inhibiting pesticides pose a health risk to farmers and consumers, though pesticide exposure pathways are not well understood. Farmers believe that cross-crop pesticide contamination between ornamental chrysanthemums and food crops is a possible source of pesticide exposure. Therefore, we used spatial analysis to test the hypothesis that cross-crop pesticide contamination may be a pesticide exposure pathway. Data on cholinesterase inhibition detection on food crops from 2006 to 2008 were spatially correlated with crop field areas and chrysanthemum cultivation areas. Statistical analysis was used to determine factors that influence the likelihood of cholinesterase inhibition detection on a crop. Our results show that the application of cholinesterase-inhibiting pesticides to a food crop contributed significantly to the likelihood that the crop would exhibit cholinesterase inhibition, but accounted for less than $10 \%$
\end{abstract}

R. A. Dunn $(\bowtie) \cdot$ W. Songskiri $\cdot$ P. Thunyapar

King Mongkut's University of Technology Thonburi, 126

Pracha-utid Rd., Bangmod, Thungkru, Bangkok 10140, Thailand

e-mail: ra2dunn@gmail.com

R. A. Dunn • C. L. Anderson • M. F. Walter · T. S. Steenhuis

Department of Biological and Environmental Engineering, Cornell University, Riley Robb Hall, Ithaca, NY 14853, USA

C. L. Anderson

e-mail: cla28@cornell.edu

M. F. Walter

e-mail: mfw2@cornell.edu

T. S. Steenhuis

e-mail: tss1@cornell.edu

C. Srimanee

Far Eastern University, 120 Mahidol Rd., Haayyaa, Muang, Chiang Mai 50200, Thailand of the total cases of detection. Demonstration of cross-crop pesticide contamination is given by greater detection for crops grown closer to chrysanthemum cultivation areas, crops tested on days of the week when samples were taken directly from the field based on proximity to chrysanthemum cultivation, and crops of species with more exposed edible parts. Mechanical barriers may be useful in reducing the risk of cross contamination.

Keywords Cholinesterase inhibiting pesticides $\cdot$ Pesticide drift - Cross-crop pesticide contamination - Food cultivation . Flower cultivation · Chrysanthemum · Intercropping · GIS analysis $\cdot$ Thailand

\section{Introduction}

Development efforts to improve farmer livelihoods, agricultural sustainability, and food security encompass a large range of often conflicting approaches, which spotlight new problems and concerns as they are implemented. In northern Thailand, development organizations including the Thai Royal Project Foundation (hereafter referred to as the Foundation) have introduced new species and cultivation methods in order to eradicate opium poppy cultivation and decrease deforestation while increasing productivity and profitability (Trebuil et al. 2006). In the 1960s, the Foundation introduced ornamental chrysanthemums to communities located in Doi Inthanon National Park (hereafter referred to as the Park), located in Chiang Mai province (Fig. 1). The chrysanthemums, grown in 2-m-wide greenhouse structures covered in plastic sheeting (Fig. 2), require heavy pesticide use, including cholinesterase inhibiting pesticides. Although the Foundation no longer sponsors chrysanthemum cultivation, chrysanthemums remain a popular crop because they provide a relatively large, stable, and continuous source of income. However, the 
use of cholinesterase inhibiting pesticides in northern Thailand and other developing areas has lead to increasing concerns about farmer and food safety and environmental impact (Ecobichon 2001; Schreinemachers et al. 2011; Thapinta and Hudak 2000).

Cholinesterase inhibiting pesticides, encompassing carbamates and organophosphates, present health risks to both farmers and consumers. These pesticides disrupt the nervous system by preventing the cholinesterase enzyme from breaking down acetylcholine. The buildup of acetylcholine in humans is associated with weakness, nausea, muscle twitching, and paralyzed breathing, in addition to neuropsychiatric symptoms including personality change, concentration and memory impairment, language disorder, and increased suicidal tendencies (Davies et al. 2000; Jokanovi'c and Kosanovi'c 2010; Stallones and Beseler 2002). Several studies have shown evidence that cholinesterase inhibiting pesticides are leading to health problems in agricultural communities in developing countries (Leilanie Lu 2005; McKinlay et al. 2008; Panuwet et al. 2009). In Thailand, the national report on health (Wibulpolprasert 2005) showed cholinesterase inhibition and pesticide poisoning among farmers, and greater frequency of suicides in the rural north. Data collected by the local health clinic in the Park showed a greater incidence of cholinesterase inhibition in blood samples and complaints of symptoms from people living in communities with greater chrysanthemum cultivation (Dr. K. Cheprengprai, personal communication, August 8, 2008).

Despite growing concern over cholinesterase inhibiting pesticide exposure, the understanding of pesticide exposure pathways is limited and contradictory. A review of the environmental and economic costs of pesticide use lists cross-crop pesticide contamination as a major problem associated with pesticide use (Pimentel et al. 1992), but cross-crop pesticide contamination is seldom discussed as a possible exposure pathway of pesticide poisonings in developing countries. Instead, research on farmer exposure to pesticides has focused on self-poisonings (Bertolote et al. 2006; Jeyaratnam 1990), as a cause rather than as an effect of pesticide exposure, or on assessing the personal protection knowledge and application practices of farmers (Hurtig et al. 2003; Ibitayo 2006; Mekonnen and Agonafir 2002; Plianbangchang et al. 2009; Recena et al. 2006; Salameh et al. 2004). These studies report that agricultural workers do not follow the recommended safety procedures when mixing, applying, and disposing of pesticides. However, research in Thailand has indicated that following recommended application safety practices may not significantly decrease exposure, indicating that other pathways might contribute to human exposure to these chemicals (Kunstadter et al. 2007; Plianbangchang et al. 2009). In addition, the Foundation, which measures cholinesterase inhibition on food crops before buying the crops for marketing and distribution, has detected cholinesterase

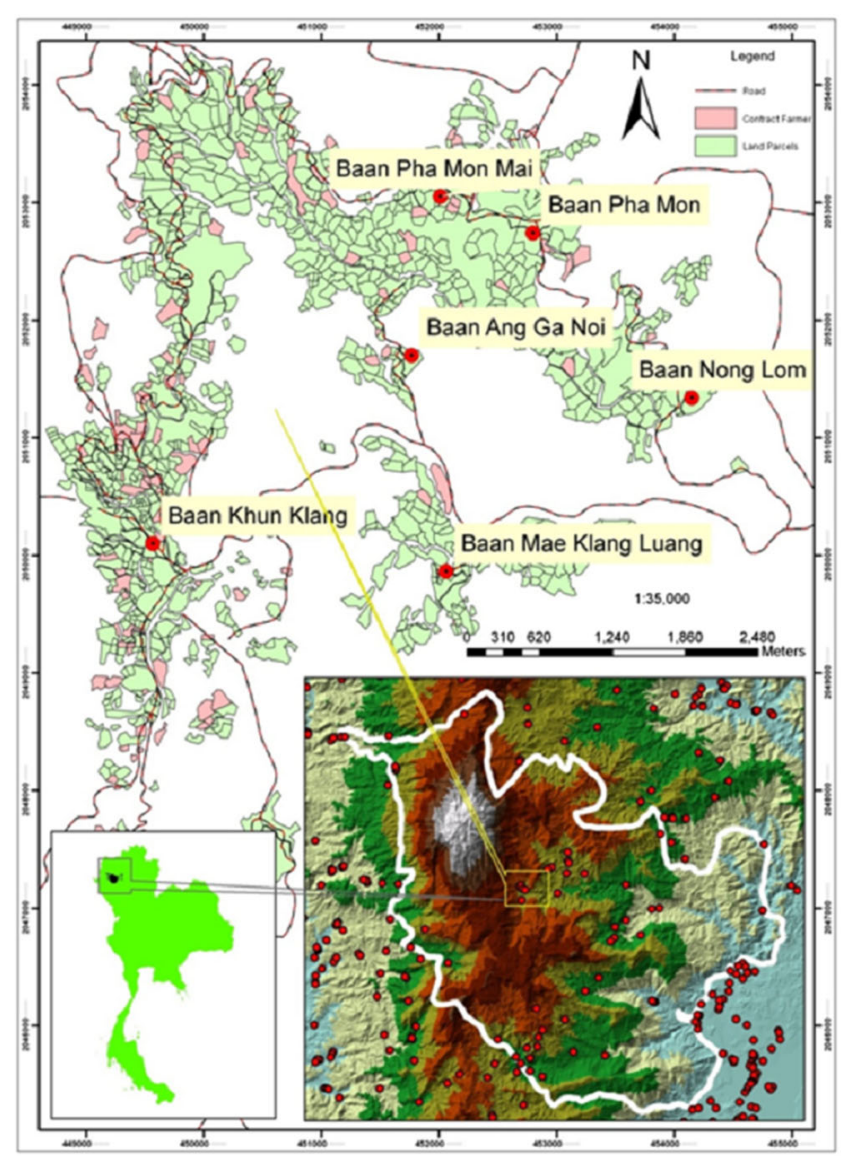

Fig. 1 Location of Doi Inthanon National Park within Thailand, the focus communities Baan Khun Klang and Baan Mae Klang Luang, extent of land parcels, and Foundation contract field locations within the park

inhibition for crops that were not treated with cholinesterase inhibiting pesticides. The general consensus between Foundation extension officers and farmers is that cross-crop pesticide contamination occurs between chrysanthemums and food crops.

The implications of cross-crop pesticide contamination are far-reaching, particularly within the context of supporting small-holder farmers in developing countries. Although the concern over cross-crop pesticide contamination is substantiated by studies that demonstrate agricultural pesticide contamination of nearby ecologically sensitive areas (Maltby and Hills 2008; de Snoo 1999), farmers and extension officers within the Park require better understanding of the extent of and factors influencing cross-crop pesticide contamination within the context of small-holder agriculture, such as crop proximity or rainfall. Cross-crop pesticide contamination is of particular concern in the Park as farmers use gaps between flower cultivation structures for sustenance food crops (Fig. 2). In addition, cross-crop pesticide contamination should also be considered within the context of increased interest in promoting intercropping as a means to improve agricultural productivity, quality, and profitability (Malézieux et al. 2009; Yildirim and 
Fig. 2 a Flower cultivation greenhouses in Baan Khun Klang. b Field used for cultivation of Foundation contract crops. c Flower cultivation greenhouse directly next to sayote vine planted for subsistence needs. d Wet rice paddies in Baan Mae Klang Luang

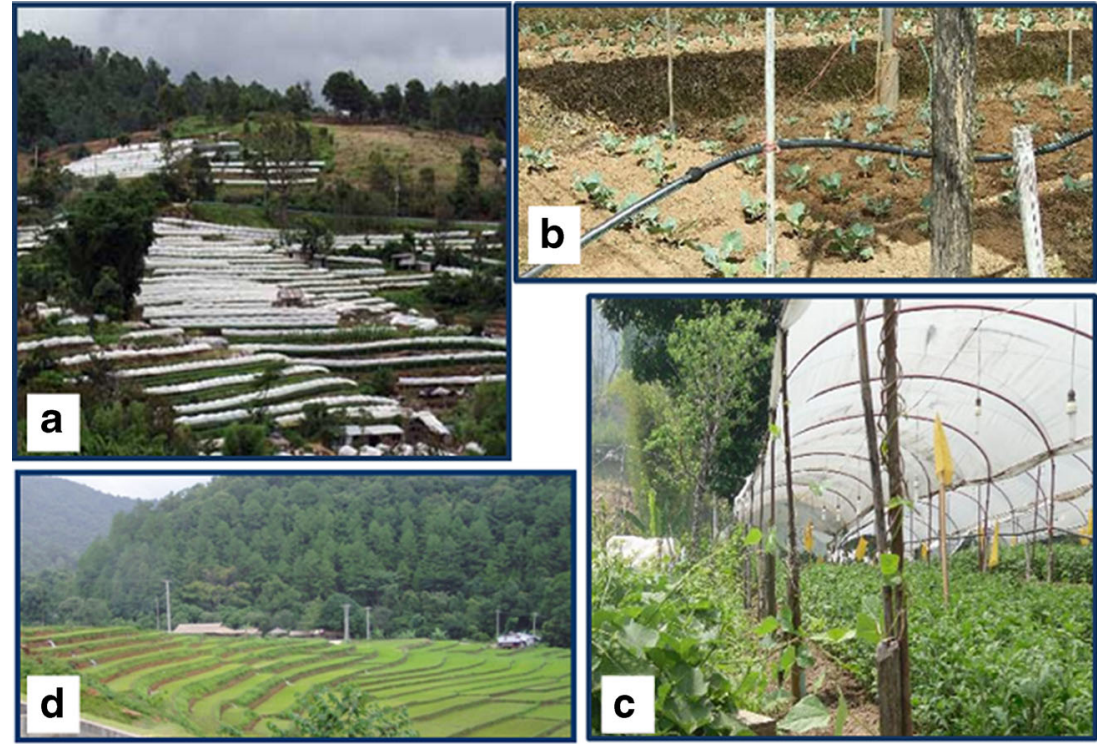

Guvenc 2005). Therefore, the objective of this research was to use spatial analysis to test the hypothesis that cross-crop contamination accounts for the detection of cholinesterase inhibition on non-treated crops presenting a possible pesticide exposure pathway.

\section{Materials and methods}

\subsection{Site description}

This research focused on an approximately $40 \mathrm{~km}^{2}$ area along the southeastern slope of Doi Inthanon National Park (Fig. 1). The Park, established in 1954 and expanded in 1972, encompasses several distinct ecological regions. Its range in altitude, which rises from 800 to 2,565 m over a total area of approximately $480 \mathrm{~km}^{2}$, provides the conditions necessary to serve several ecosystem types including dry and mixed deciduous forests, dry evergreen forest, montane forest, and peat bogs (Lykke and Barford 2000). The study area ranges in elevation from 1,000 to $1,800 \mathrm{~m}$ with slightly acidic soil with a sandy surface $(0-5 \mathrm{~cm})$ and clay subsurface $(20-25 \mathrm{~cm}$; Sahunalu et al. 1999). The area experiences a monsoonal climate with a distinct wet season from mid-May through October.

The study area contains communities representing both the Hmong and Bakinyaw (commonly referred to as Karen) ethnic minority groups. Agriculture serves as the primary occupation of those residing in area. The Hmong village of Baan Khun Klang, with a population of approximately 1,500 people, was established approximately 100 years ago. The majority of farmers in this community grow chrysanthemums, which are highly profitable and provide a continuous source of income for 2 years after their initial planting (Fig. 2a, b, c).
The remaining Bakinyaw communities, such as Baan Mae Klang Luang, are made up of approximately $250-500$ people each, and were established over 200 years ago. These communities' agricultural practices focus on wet paddy rice cultivation during the rainy season, although flower cultivation is becoming more common (Fig. 2d).

\subsection{Pesticide residue measurement}

Evaluation of the occurrence of cross-crop contamination was conducted primarily based on the contract crop quality control data compiled by the Foundation. Currently, the Foundation extends contracts to farmers to grow food crops, which are tested for pesticide residue before they are bought, packaged, distributed, and sold by the Foundation. The Foundation supplements the standard gas chromatography, gas chromatography-mass spectrometry (GC-MS), and high performance liquid chromatography (HPLC) pesticide residue quality control check conducted at its central packaging center with extensive onsite testing for cholinesterase inhibition before the crop is harvested and shipped. Cholinesterase inhibition is measured using the Gobthong Thoophom (GT) Pesticide Test Kit method (GT Trading 2004), which was developed by the Food Division of the Thai Ministry of Public Health based on the de la Huerga method (de la Huerga et al. 1952). The test kit provides a qualitative measure of cholinesterase inhibition on a scale of 0 to 5 , where each increase in the cholinesterase inhibition level detected along the colorimetric scale corresponds to an approximately $10 \%$ increase in cholinesterase inhibition (Dr. N. Jonglaekha, personal communication, February 21, 2012). For example, the GT-test kit would give a +3 reading for $0.5 \mathrm{mg} / \mathrm{kg}$ carbofuran or a +4 reading for the equivalent amount of monocrotophos, 
profenofos, or trichlorfon. The method has been extensively validated by the Thai Ministry of Health (GT Trading 2004) and the Foundation, and found to be more conservative than standard GC-MS and HPLC methods.

The methodology requires first preparing the sample and then testing the sample using the GT-kit. The matrix of the sample is dependent on the type of produce being sampled: the Foundation is interested in testing if the edible component of the crop (fruit/leaf/seed) poses a hazard to the health of the consumer. Therefore, the matrix (fruit/leaf/seed) is selected based on the part of the plant the consumer is likely to ingest. Because of its dependency on colorimetric readings and its measurement of cholinesterase inhibition rather than actual pesticide quantity, false positives are possible. In particular, the Foundation has found broccoli to give false positives (Dr. N. Jonglaekha, personal communication, February 21, 2012), and all data on broccoli were removed from the data set. Also, members of the Solanaceous family (nightshades) have been shown to exhibit cholinesterase inhibition (Orgell et al. 1958), and special care was taken to evaluate potatoes, peppers, and tomatoes to check for the likelihood of false positives, as described in the "Data analysis" section.

\subsection{Spatial correlation}

The Foundation quality control data were correlated to the area the farmers used to grow the food and chrysanthemum crops through mapping exercises and interviews with local farmers and Foundation extension agents. First, it was necessary to link the pesticide residue data to a Geographic Information System (GIS) database of the area. The farmers' contract identification numbers were used to link the farmer responsible for each contract crop to a landownership GIS file developed for the Highland Research and Development Institute (public organization) by the Agricultural Land Reform Office in 2004. These maps were provided by the Foundation and substantiated by the local farmers in informal interview settings. The correct spatial interpretation of the food crop data was further confirmed through informal review by Foundation extension officers and the farmers. Specifically, farmers and extension officers were asked to confirm land holdings and the locations of fields used for growing contract crops using the land ownership database and aerial photos of the study area taken by the Land Development Department in 2002 at a 1:4, 000 scale. The flower field locations for 2006, 2007, and 2008 were identified using a combination of visual identification on the aerial photos, consultation with community members, and geographic positioning system (GPS) data point collection.

The Foundation contract crop and the flower crop GIS databases, as well as a digital elevation model of the research area, resulted in a database through which a number of spatial factors could be extracted. Of particular interest was the distance between the contract field and the closest flower field, the density of flower fields within a given radius from the contract field, and the density of the flower fields within the contract field's contributing watershed area (Fig. 3). All data extraction from the GIS database was done using the PCI Geomatica GIS database analysis software. Data were georeferenced to the World Geodetic System 1984 (WGS84) coordinate system using the 47 North projection zone and the Universal Transverse Mercator (UTM) datum. The digital elevation model was constructed by converting a contour map (contour lines at $2 \mathrm{~m}$ intervals) of the research area. Parcel data were then stored as vector data in shape format with a primary key set for each parcel to be identified with a unique number. The contract fields were located within this data set and extracted and stored in a new shape file. Attribute data were created for each parcel, including specifications as to whether flowers had been grown in that parcel for 2006, 2007, and 2008.

The nearest distance values (ND) were extracted using basic PCI Geomatica GIS data analysis functions. The distance between the contract field and the closest flower field was found by measuring the distance from the center of the contract field to the center of the closest flower field (Fig. 3a). This was accomplished by locating the contract fields and their closest flower field and identifying their respective centroids. These centroid points were used as the basis to calculate the shortest distance between a contract parcel and a flower parcel. For contract crops grown in a field also used for growing flowers a closest distance of zero was used.

The density of flower fields within a given radius from the contract field was determined by setting a buffer zone around contract fields with radii: 10, 50, 100, and $200 \mathrm{~m}$ (Fig. 3b). Each buffer file was created from the contract shape file, and then overlayed onto the parcel map to extract the area of each parcel encompassed by the buffer area. These datasets were then imported into a Microsoft Access database, which tracked the unique parcel identification numbers and the presence of flower cultivation within each of the parcels for 2006 to 2008. Thus, changes in the flower cultivation database could be made without necessitating a recalculation of the percent areas using the GIS database. An Access query was then used to determine the fraction of flower cultivation areas within the respective contract field buffer zones.

The density of flower fields within the contract field's contributing watershed area required more specialized analysis of the Doi Inthanon area digital elevation model. Specifically, the threshold function was used to determine the smallest possible watershed areas within the study site. The contributing watershed areas for each contract field were then manually digitized from the lowest point in that parcel to the place indicated by the contour line that the slope direction changes. These areas were then converted into shape files with the associated parcel identification number and then overlaid on the field location maps (Fig. 3c). The fraction of each field 
Fig. 3 a Example of centroid locations and nearest distance lines of contract crop and a flower cultivation area for 2008. b Example of buffer extent for $200 \mathrm{~m}$ buffer radius of contract crop land parcels with flower cultivation land parcels for 2008. c Example of watershed extent of contract crop land parcels with flower cultivation land parcels for 2008

with its associated parcel identification number within each watershed was then extracted. Similarly to the buffer area data, the watershed area data were imported into Access, and the fraction of flower cultivation within the watershed area was calculated.

\subsection{Data analysis}

The database was compiled by correlating the two datasets in Access using each food crop (single species grown in distinct land parcel with unique harvest date) as the focus for linking the different sets of data. An additional data set was compiled on the pesticides applied to each crop, as recorded by the Foundation, by identifying the active ingredients of the pesticides applied to each crop and determining whether or not they exhibit cholinesterase inhibition. Query design was used to construct a data set including: crop number, land parcel number, cholinesterase inhibition results, cholinesterase inhibiting pesticide application, test date, harvest date, nearest distance to flower cultivation area, fraction of flower cultivation areas in buffer zones and watershed, harvest year and month, and the day of the week the test was conducted. The data were exported to Microsoft Excel for statistical analysis using the R statistical package add-in for Excel. The data were checked, and all duplicates and incomplete entries were removed. In addition, because the cholinesterase inhibition results cannot be correlated to the quantity of pesticide residue on a sample, as the method is more sensitive to some pesticides than others, the cholinesterase inhibition test results were represented binomially as detected (1) versus not detected (0).

Statistical analysis was run on the remaining data set, consisting of cholinesterase inhibition detection results for 271 crops tested in 66 distinct land parcels from 2006 through 2008. First, single variable analysis of variance (ANOVA) was used to determine whether cholinesterase inhibition detection varies significantly within the variable categories specified in Table 1 . The results of this analysis provided the starting point for a multiple linear regression analysis looking first at main effects and then adding interaction effects. Dummy variables were assigned to categorical data as specified in Table 1. In addition to the analysis summarized in Table 1, an additional multiple linear regression main effects analysis was conducted categorizing species by those that never exhibited cholinesterase inhibition, those that exhibited cholinesterase inhibition and are members of the Solanaceous family (nightshades), and those that exhibited cholinesterase inhibition and are not members of the Solanaceous family. This analysis was used
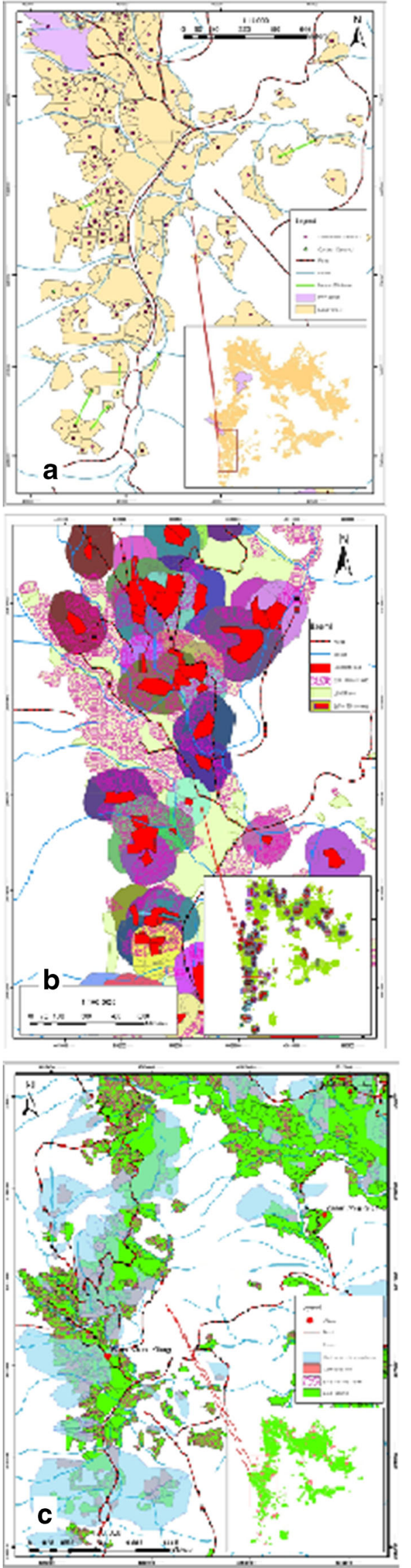
Table 1 Summary of variable categorizations used for ANOVA and regression analysis of non-spatial and spatial factors influencing cholinesterase (ChE) inhibition detection for Thai Royal Project Foundation contract crops

\begin{tabular}{|c|c|c|c|}
\hline Variable & Description & $\begin{array}{l}\text { ANOVA Categories Showing Significant } \\
\text { Difference }\end{array}$ & $\begin{array}{l}\text { Regression Categorization } \\
\text { (Dummy Variable) }\end{array}$ \\
\hline \multirow{2}{*}{$\begin{array}{l}\text { ChE Inhibiting Pesticide } \\
\text { Application }\end{array}$} & \multirow{2}{*}{$\begin{array}{l}\text { Record of which pesticides the farmer } \\
\text { applied to the crop cross-referenced to } \\
\text { whether the pesticide exhibits } \mathrm{ChE} \\
\text { inhibiting effects. }\end{array}$} & One or more applications & One or more applications (1) \\
\hline & & No applications & No applications $(0)$ \\
\hline \multirow[t]{2}{*}{ Species } & \multirow{2}{*}{$\begin{array}{l}\text { Species of the crop cultivated (broccoli } \\
\text { removed because of propensity for } \\
\text { false positives) }\end{array}$} & $\begin{array}{l}\text { High (tomato, chili, cabbage, celery and Japanese } \\
\text { onion) }\end{array}$ & High Average (1) \\
\hline & & $\begin{array}{l}\text { Low (cherry tomato, fennel, cucumber, pea, } \\
\text { radish, carrot, potato, pepper, and zucchini) }\end{array}$ & Low Average (0) \\
\hline \multirow[t]{2}{*}{ Day of Week } & \multirow{2}{*}{$\begin{array}{l}\text { Day of the week the crop was tested for } \\
\text { ChE inhibition }\end{array}$} & High (Sunday, Tuesday, Thursday) & High Average (1) \\
\hline & & Low (Monday, Wednesday, Friday, Saturday) & Low Average (0) \\
\hline \multirow[t]{2}{*}{ Month } & \multirow[t]{2}{*}{ Month the crop was harvested } & Month (January-December) & \multirow[t]{2}{*}{ Not Applicable } \\
\hline & & Season (Hot, Rainy, Cool) & \\
\hline \multirow[t]{3}{*}{ Year } & \multirow[t]{3}{*}{ Year the crop was harvested } & \multirow[t]{3}{*}{$2006,2007,2008$} & $2006\left(\begin{array}{llllll}0 & 0\end{array}\right)$ \\
\hline & & & $2007\left(\begin{array}{ll}1 & 0\end{array}\right)$ \\
\hline & & & $2008\left(\begin{array}{ll}0 & 1\end{array}\right)$ \\
\hline \multirow[t]{2}{*}{ Nearest Distance (ND) } & \multirow{2}{*}{$\begin{array}{l}\text { Nearest distance from centroid of land } \\
\text { parcel to centroid of closest land parcel } \\
\text { used for chrysanthemum cultivation }\end{array}$} & $\mathrm{ND}<15 \mathrm{~m}$ & $\mathrm{ND}<15 \mathrm{~m}(1)$ \\
\hline & & $\mathrm{ND}>15 \mathrm{~m}$ & $\mathrm{ND}>15 \mathrm{~m}(0)$ \\
\hline \multirow{2}{*}{$\begin{array}{l}\text { Buffer (B\#, where \# is } \\
\text { width of buffer zone) }\end{array}$} & \multirow{2}{*}{$\begin{array}{l}\text { Fraction of flower cultivation land parcel } \\
\text { area within buffer zone around crop land } \\
\text { parcel }\end{array}$} & $\mathrm{B} \#>0.5$ & \multirow[t]{2}{*}{ Not Applicable } \\
\hline & & $\mathrm{B} \#<0.5$ & \\
\hline \multirow[t]{2}{*}{ Watershed (WS) } & \multirow{2}{*}{$\begin{array}{l}\text { Fraction of flower cultivation land parcel } \\
\text { area within watershed of crop land } \\
\text { parcel }\end{array}$} & $\mathrm{WS}>0.1$ & WS $>0.1(1)$ \\
\hline & & $\mathrm{WS}<0.1$ & $\mathrm{WS}<0.1(0)$ \\
\hline
\end{tabular}

to test if crops from the Solanaceous family contributed significantly to cholinesterase inhibition detection, indicating whether or not these species might be giving false positives.

\section{Results and discussion}

The results of the ANOVA and regression analysis of cholinesterase inhibition detected on Foundation contract crops, shown in Fig. 4, support the hypothesis that cross-crop pesticide contamination is occurring between chrysanthemum and food crops and that drift is the primary transport mechanism. First, although the use of a cholinesterase inhibiting pesticide directly on a contract crops showed the largest difference in average level of cholinesterase inhibition detected, the direct use of these pesticides only accounts for 6 of the 63 occurrences of cholinesterase inhibition detection in the data set. Analysis of spatial factors (nearest distance, buffer, and watershed) showed that nearest distance (ND) of less than $15 \mathrm{~m}$ and a $50 \%$ or greater fraction of chrysanthemum cultivation within a $10-\mathrm{m}$ buffer zone were equivalent predictors of increased occurrences of cholinesterase inhibition detection. The interaction effect model indicated, however, that nearest distance did not have a significant effect except for species whose edible components are exposed. Months and seasons did not exhibit significant differences, indicating lower likelihood that runoff is a significant transport mechanism in cross-crop cholinesterase inhibiting pesticide contamination. Cholinesterase inhibition decreased with each year, which is likely due to the establishment of the quality control check and the resulting changes in how fields are selected for contract crop cultivation. Finally, differences amongst results from different days of the week uncovered variations in sampling methods such that these differences may be attributed to chrysanthemum cultivation proximity. These results are discussed in more detail below.

The results show cholinesterase inhibition detection on crops where cholinesterase inhibiting pesticides were applied. However, the use of these pesticides directly on contract crops accounts for less than $10 \%$ of occurrences of cholinesterase inhibition detection in the data set. The presence of cholinesterase inhibiting compounds on 57 crops that were not treated with cholinesterase inhibiting pesticides indicates that there is an alternate path of exposure not accounted for by direct pesticide application. These results also highlight the need for greater concern over the presence of subsistence crops within the flower cultivation areas (Fig. 2). If farmers presume that as long as they are using the pesticides as indicated they do not need to worry about pesticide persistence, they may have a false sense of security with respect to the safety of their 
Fig. 4 a Results of analysis of variance (ANOVA) comparing average pesticide residue levels on Thai Royal Project Foundation produce crops grown on Doi Inthanon and harvested during 2006 to 2008. b Multiple regression coefficients of main effects (main) and interaction effects (int) between nearest distance and species (ND*Species), where “*”, “**”, and "****" indicate coefficient significance levels of $0.05,0.01$, and 0.00 , respectively. $C h E$ cholinesterase

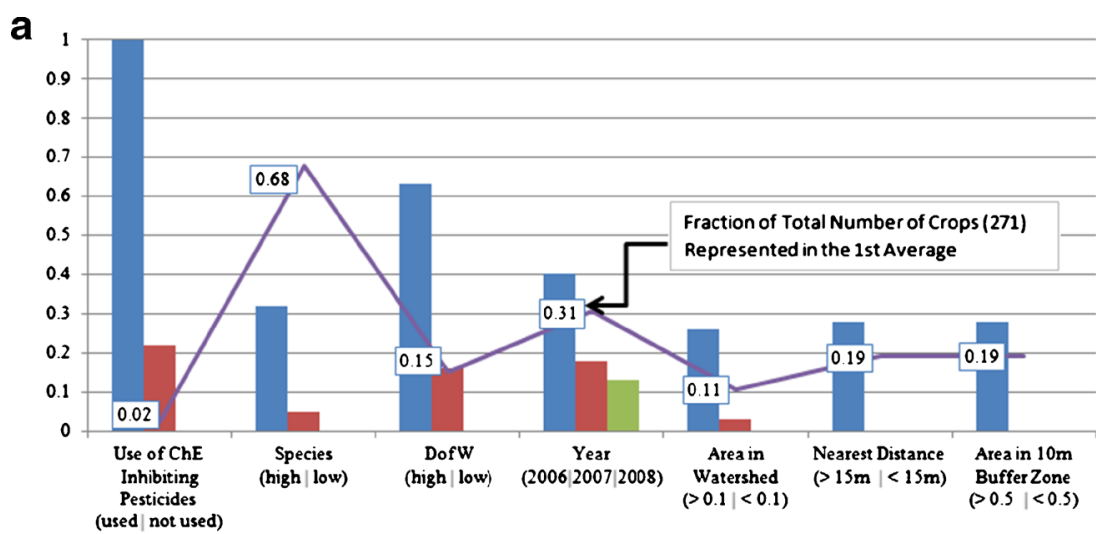

b

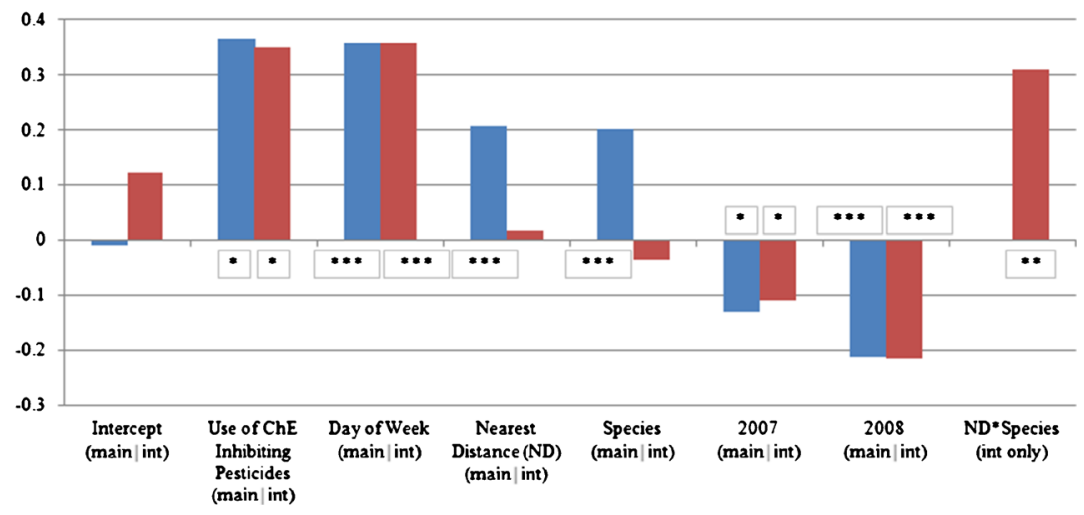

food crops. If it is assumed that the farmers and extension officers have recorded the application rates and methods accurately, then the use of these pesticides according to the Foundation regulations and industry standards should not have resulted in such high rates of cholinesterase inhibition detection.

Of the spatial factors analyzed, nearest distance and the fraction of chrysanthemum cultivation in a buffer zone of $10 \mathrm{~m}$ and watershed showed significantly different cholinesterase inhibition detection. Significant differences were not seen between cholinesterase inhibition detection in groups divided according to fraction of chrysanthemum cultivation within a buffer zone larger than $10 \mathrm{~m}$ (50, 100, and $200 \mathrm{~m})$. In addition, although grouping the results of the percent of flower cultivation within the contract crop's watershed area above and below $10 \%$ resulted in a significant difference between the average cholinesterase inhibition detected on these crops, the watershed variable coefficient was not statistically significant within the main effects regression model and was dropped. However, a nearest distance of less than $15 \mathrm{~m}$ and a $50 \%$ or greater presence chrysanthemum cultivation within a $10-\mathrm{m}$ buffer zone both resulted in a greater rate of cholinesterase inhibition detection. In fact, the two groupings were exactly equivalent, resulting in a calculation error if both variables were included in the regression analysis. For simplicity, later references to the spatial results in this discussion only refer to nearest distance (ND).

The crop species factor was also found to result in significant differences between cholinesterase inhibition detection. First, because of the nature of the cholinesterase inhibition test, it was necessary to ensure that crops from the Solacenous family were not likely to be false positives (Orgell et al. 1958). Crop species were grouped according to whether any crop of that species had ever exhibited cholinesterase inhibition. None of the crops of cherry tomato (22 crops), bell pepper ( 4 crops), or potato (1 crop) ever exhibited cholinesterase inhibition; therefore, it was not necessary to analyze these crops for false positives. However, crops of tomato (5 of 26) and chili pepper (4 of 17) had tested positive for cholinesterase inhibition. An ANOVA analysis was used to compare the averages for these crops versus other crops for which cholinesterase inhibition was detected. There was a significant difference found between these groups, but the Solacenous food crops were found to have a lower detection rate than those of the other food crops. An additional regression analysis without interaction effects was run grouping crops never exhibiting cholinesterase inhibition detection, Solacenous crops and other crops. This analysis showed that the inclusion of a Solacenous species category was not significant within the resulting model. Therefore, this variable was removed from the analysis, and 
food crops were grouped according to high cholinesterase inhibition detection (tomato, chili, cabbage, celery, and Japanese onion) and low cholinesterase inhibition detection (cherry tomato, fennel, cucumber, pea, radish, carrot, potato, pepper, and zucchini). The combination of the nearest distance and species variables gave interesting results in the regression interaction analysis.

The nearest distance (ND) and species interaction variable (ND*Species) resulted in a statistically significant coefficient that contributes positively to the interaction regression model. Furthermore, the combination of these terms leads to a nonsignificant contribution of the individual terms to the regression model. The interaction of these terms gives interesting insight into possible means to reduce the effects of cross-crop pesticide contamination. Specifically, neither factor contributes significantly to increases in cholinesterase inhibition detection unless both factors are present. That is, proximity to a high pesticide use area only increases cholinesterase inhibition detection if a particular species of crop is being grown. The difference between the high and low cholinesterase inhibition detection species is that the edible portions of the former (tomato, chili, cabbage, celery, and Japanese onion) are much more exposed than those of the latter (cherry tomato, fennel, cucumber, pea, radish, carrot, potato, bell pepper, and zucchini). These results support the hypothesis that drift contributes to cross-crop pesticide contamination, but also indicate that mechanical barriers between pesticide intensive crops and food crops may decrease these effects. This observation is particularly important as farmers living in areas with high levels of chrysanthemum cultivation are inclined to grow edible greens with large leaf surface areas (such as sayote, Fig. 2b) and disinclined to establish pesticide free zones.

The analysis of months and seasons did not indicate any significant differences among these groupings. Farmers had indicated a need to use more pesticides during the dry season, and it was generally thought by local stakeholders that there might be spikes in pesticide residue in the dry season or a spike in May and June at the start of the rainy season. However, on a month to month basis the ANOVA analysis showed no statistically significant difference in cholinesterase inhibition detection levels. Months grouped by season also did not show any significant differences. These results, as well as the fact that watershed did not contribute significantly to the regression model, suggest that neither the presence nor absence of rainfall significantly impacts cross-crop pesticide contamination.

Of further interest, the ANOVA and regression analysis on the differences in pesticide levels detected in 2007 and 2008 showed a decrease in pesticide contamination of contract crops from 2006. There are two likely explanations for this trend. First, interviews with Foundation extension officers found that contract assignments were being made explicitly with the location of contract field proximity to chrysanthemum flower cultivation areas in mind. Second, as farmers had to adjust to the new crop pesticide safety quality control standards, they may have been changing their pesticide application practices. Furthermore, cholinesterase inhibiting pesticides were recorded as being used on contract crops only once after 2006.

Finally, the day of the week, a sample was tested showed a strong effect on the regression model, as seen in Fig. 4. Specifically, samples tested showed Sunday, Tuesday, and Thursday to have the highest average residue detection, whereas Monday, Wednesday, and Friday had the lowest. These results did not align with stakeholder expectations, which predicted spikes on Wednesday and Saturdays as those are the days farmers typically apply pesticides in flower cultivation areas. Instead, further interviews with Foundation extension agents indicated that these differences may be attributable to how samples of produce are taken on different days of the week. Monday, Wednesday, Friday, and Saturday are the days the Foundation receives shipments of crates of produce from the contract farmers and tests on these shipments are run on random samples taken from the crates. These tests made up $78 \%$ of the tests run from 2006 through 2008. In contrast, the tests run on the other days are not random samples, but instead are taken by Foundation extension officer directly from the field where the contract crop is cultivated.

The addition of the day of the week term to the regression model, therefore, may be providing an imperfect dampening for noise caused by a lack of specificity in the spatial data. Specifically, the direct sampling method used on Sunday and Tuesdays allowed extension officers the opportunity to select samples from areas that seem particularly likely to have pesticide contamination. Extension officers typically made these selections based on crop proximity to chrysanthemum cultivation areas. The spatial data collected for the data analysis attributed chrysanthemum cultivation to an entire land parcel and did not discriminate for or against samples collected along borders of cultivation areas. Thus, nearest distance measurements of $0 \mathrm{~m}$ may include samples grown directly next to chrysanthemum cultivation areas or samples from the opposite end of the same land parcel. Day of the week corrects for some of the non-detected results from sampling within land parcels with a nearest distance less than $15 \mathrm{~m}$ where samples may have been taken from farther away.

Thus, the results of this analysis substantiate the concerns that human exposure to cholinesterase inhibiting pesticides may be occurring due to food crop pesticide contamination via cross-crop contamination with chrysanthemum cultivation. Again, these results are particularly significant because walk through surveys of flower cultivation areas showed that farmers are planting food for home use directly next to and between the flower cultivation areas, whereas the Foundation contract crops are planted in independent cropping areas (see Fig. 2). Therefore, the exposure of farmers and their families to the pesticides applied to the flower crops through cross-crop 
pesticide contamination of their subsistence crops are likely much higher than indicated by the cholinesterase inhibition detected on the contract crops. It is also important to note that several of the pesticides used in this area, such as captan and cholrothalonil, were found to be listed as acutely toxic and/or carcinogenic, but these were not cholinesterase inhibitors. Thus, understanding how pesticides are moving from one crop to another is as critical for the problems that are not detected by the tests, as well as for those that are.

\section{Conclusions}

The results of this study indicate that the cross-crop pesticide contamination may be a significant pesticide exposure route for farmers and their families in Doi Inthanon National Park. Specifically, the crops planted by farmers on contract with the Thai Royal Project Foundation are subject to contamination from nearby intensive pesticide use on chrysanthemum crops. The use of cholinesterase inhibiting pesticides directly on a crop was found to result in a higher average detected residue level. The detection of cholinesterase inhibition on the contract crops where the farmer was known to use cholinesterase inhibiting pesticide is significant because these pesticides were applied under conditions of monitoring and control. Thus, following prescribed pesticide application methods may provide a false sense of safety in this area with respect to the longevity of cholinesterase inhibiting pesticide on crops. In addition, these crops accounted for less than $10 \%$ of the crops with cholinesterase inhibition detection. Multiple linear regression analysis showed that the interaction between the proximity of a crop to chrysanthemum cultivation areas, which require high pesticide use, and crop species resulted in a significant contribution to the likelihood of cholinesterase inhibition detection on that crop. Interestingly, the species which interacted with nearest distance to produce these results were species with edible parts with greater exposed surface. That is, celery, which is fully exposed, showed more incidents of cholinesterase inhibition than zucchini, which develops under large, overhanging leaves. These results suggest that reducing cross-crop pesticide contamination is not entirely dependent on maintaining a minimum distance between crops, but that mechanical barriers might reduce the extent of contamination.

Because cross-crop pesticide contamination may be a significant pesticide exposure route for small-holder farmers and their families, further research and planning with small-holder agricultural communities should be conducted. Awareness of the risks of cross-crop pesticide contamination is particularly important in communities where inter-cropping is already popular or is being encouraged. In particular, local subsistence crops may be very susceptible to cross-crop pesticide contamination because, unlike contract crops grown in centralized cultivation areas, local subsistence crops are typically planted in gaps between other cultivation areas. Therefore, work should be done to encourage small-holder farmer understanding that cholinesterase inhibiting pesticides may not be safe for use on or near food crops, even when applied according to recommended methods. In addition, small-holder farmers should be made aware of cross-crop pesticide contamination such that this knowledge can inform land management plans at the individual and community scale to help ensure local food safety. Finally, development agencies should take current pesticide intensive crop preferences and inter-cropping practices into account when considering the introduction of new pesticide intensive crops or new inter-cropping practices to farmers.

Acknowledgments This research was funded by the U.S. Department of Education through the Fulbright-Hays Doctoral Dissertation Research Abroad Fellowship, King Mongkut's University of Technology Thonburi's Royal Project Initiatives Program, Chulalongkorn University's Empowering Networks of International Thai Studies program, and Cornell University's Richard Bradfield Research Award and International Research Travel Grants. This research would not have been possible without the support of the National Research Council of Thailand. The authors would also like to thank Ms. Branee Thanatwan, Mr. Nilaan Bakpaksaan, Mr. Manut Salee, Mr. Boontum Jarunsongsuem, and Mr. Boontawng Kajeewongwilai for their assistance collecting the data used for this research. Finally, this paper was much improved with the help of anonymous reviewers, and assistance from Dr. Asawin Meechai, Dr. Kurt Frey, and Dr. Xuemao Zhang.

\section{References}

Bertolote JM, Fleischmann A, Eddleston M, Gunnell D (2006) Deaths from pesticide poisoning: a global response. Br J Psychiatr 189(3): 201-203. doi:10.1192/bjp.bp.105.020834

Davies R, Ahmed G, Freer T (2000) Chronic exposure to organophosphates: background and clinical picture. Adv Psychiatr Treat 6(3): 187-192. doi:10.1192/apt.6.3.187

de la Huerga J, Yesinick C, Popper H (1952) Colorimetric method for the determination of serum cholinesterase. Am J Clin Pathol 22(11): 1126

de Snoo G (1999) Unsprayed field margins: effects on environment, biodiversity and agricultural practice. Landsc Urban Plan 46(1): 151-160. doi:10.1016/S0169-2046(99)00039-0

Ecobichon DJ (2001) Pesticide use in developing countries. Toxicology 160(1):27-33. doi:10.1016/S0300-483X(00)00452-2

GT Trading (2004) Introduction to GT test kit. http://www.gttestkit.com/ gttestkit_eng/intro_method.htm. Accessed 4 April 2011

Hurtig AK, San Sebastian M, Soto A, Shingre A, Zambrano D, Guerrero W (2003) Pesticide use among farmers in the Amazon basin of Ecuador. Arch Environ Health 58(4):223-230. doi:10.3200/ AEOH.58.4.223-228

Ibitayo OO (2006) Egyptian farmers' attitudes and behaviors regarding agricultural pesticides: implications for pesticide risk communication. Risk Anal 26(4):989-996. doi:10.1111/j.15396924.2006.00794.x

Jeyaratnam J (1990) Acute pesticide poisoning: a major global health problem. World Health Stat Q 43(3):139-144 
Jokanovi'c M, Kosanovi'c M (2010) Neurotoxic effects in patients poisoned with organophosphorus pesticides. Environ Toxicol Pharmacol 29(3): 195-201. doi:10.1016/j.etap.2010.01.006

Kunstadter P, Prapamontol T, Mevatee U, Thawsirichuchai R, Yangyernkun W (2007) Seasonal and annual changes in pesticide exposure: Hmong highland villagers in Northern Thailand. In: Kunstadter P (ed) Pesticides in Southeast Asia. Sanga Sabhasri Research Foundation, Bangkok, pp 109-130

Leilanie Lu J (2005) Risk factors to pesticide exposure and associated health symptoms among cut-flower farmers. Int J Environ Health Res 15(3):161-169. doi:10.1080/09603120500105638

Lykke AM, Barford AS (2000) Studies and mapping of ecosystem diversity in Northern Thailand. Aims and methods. Research Centre on Forest and People in Thailand. University of Aarhus, Denmark: Danish Institute of Agricultural Sciences. http://www. forestandpeople.org. Accessed $21 \mathrm{Feb} 2007$

Malézieux E, Crozat Y, Dupraz C, Laurans M, Makowski D, OzierLafontaine H, Rapidel B et al (2009) Mixing plant species in cropping systems: concepts, tools and models. A review. Agron Sustain Dev 29(1):43-62. doi:10.1051/agro:2007057

Maltby L, Hills L (2008) Spray drift of pesticides and stream macroinvertebrates: experimental evidence of impacts and effectiveness of mitigation measures. Environ Pollut 156(3):1112-1120. doi:10. 1016/j.envpol.2008.04.013

McKinlay R, Plant JA, Bell JNB, Voulvoulis N (2008) Calculating human exposure to endocrine disrupting pesticides via agricultural and non-agricultural exposure routes. Sci Total Environ 398:1-12. doi:10.1016/j.scitotenv.2008.02.056

Mekonnen Y, Agonafir T (2002) Pesticide sprayers' knowledge, attitude and practice of pesticide use on agricultural farms of Ethiopia. Occup Med 52(6):311-317. doi:10.1093/occmed/52.6.311

Orgell WH, Vaidya KA, Dahm PA (1958) Inhibition of human plasma cholinesterase in vitro by extracts of solanaceous plants. Science 128(3332):1136-1137. doi:10.1126/science.128.3332.1136

Panuwet P, Prapamontol T, Chantara S, Barr DB (2009) Urinary pesticide metabolites in school students from Northern Thailand. Int
J Hyg Environ Health 212(3):288-297. doi:10.1016/j.ijheh.2008. 07.002

Pimentel D, Acquay H, Biltonen M, Rice P, Silva M, Nelson J, Lipner V et al (1992) Environmental and economic costs of pesticide use. Bioscience 42(10):750-760. doi:10.2307/1311994

Plianbangchang P, Jetiyanon K, Wittaya-areekul S (2009) Pesticide use patterns among small-scale farmers: a case study from Phitsanulok, Thailand. Southeast Asian J Trop Med Public Health 40(2):401-410

Recena MCP, Caldas ED, Pires DX, Pontes ERJC (2006) Pesticides exposure in Culturama, Brazil - knowledge attitudes, and practices. Environ Res 102:230-236. doi:10.1016/j.envres.2006.01.007

Sahunalu P, Teejuntuk S, Sungpalee C, Methavararuk A (1999) Study on the vegetation zonation in Doi Inthanon National Park and its application to environmental education. http://www.nacsj.or.jp/pn/ houkoku/h10/h10-no15.html. Accessed 4 April 2011

Salameh PR, Baldi I, Brochard P, Abi Saleh B (2004) Pesticides in Lebanon: a knowledge, attitude, and practice study. Environ Res 94:1-6. doi:10.1016/S0013-9351(03)00092-6

Schreinemachers P, Sringarm S, Sirijinda A (2011) The role of synthetic pesticides in the intensification of highland agriculture in Thailand. Crop Prot 30(11):1430-1437. doi:10.1016/j.cropro.2011.07.011

Stallones L, Beseler C (2002) Pesticide illness, farm practices, and neurological symptoms among farm residents in Colorado. Environ Res 90(2):89-97. doi:10.1006/enrs.2002.4398

Thapinta A, Hudak PF (2000) Pesticide use and residual occurrence in Thailand. Environ Monit Assess 60(1):103-114. doi:10.1023/ A:1006156313253

Trebuil G, Ekasingh B, Ekasingh M (2006) Agricultural commercialisation, diversification, and conservation of renewable resources in northern Thailand highlands. Moussons 9-10:131-155

Wibulpolprasert S (2005) Thailand health profile 2001-2004. Bureau of Policy and Strategy, Ministry of Public Health, Bangkok

Yildirim E, Guvenc I (2005) Intercropping based on cauliflower: more productive, profitable and highly sustainable. Eur J Agron 22(1):1118. doi:10.1016/j.eja.2003.11.003 